\title{
Optimizasyon Tabanlı FIR Süzgeç Tasarımlarında Performans Analizi
}

\author{
Mehmet Fatih Karakaşs, ${ }^{1,2}$, Fatma Latifoğlu ${ }^{2}$ \\ 1* Erciyes Üniversitesi, Mühendislik Fakültesi, Biyomedikal Mühendisliği Bölümü, Kayseri, Türkiye \\ 1*Erzincan Binali Yıldırım Üniversitesi, Mühendislik Fakültesi, Biyomedikal Mühendisliği Bölümü, Erzincan, Türkiye \\ (ORCID: 0000-0003-0233-6141), karakasmf@gmail.com \\ ${ }^{2}$ Erciyes Üniversitesi, Mühendislik Fakültesi, Biyomedikal Mühendisliği Bölümü, Kayseri, Türkiye \\ (ORCID: 0000-0003-2018-9616), flatifoglu@erciyes.edu.tr
}

(İlk Geliş Tarihi 28 Haziran 2021 ve Kabul Tarihi 15 Aralık 2021)

(DOI: 10.31590/ejosat.958748)

ATIF/REFERENCE: Karakas, M. F., Latifoglu F. (2021). Optimizasyon Tabanlı FIR Süzgeç Tasarımlarında Performans Analizi. Avrupa Bilim ve Teknoloji Dergisi, (31), 8-22.

\section{$\ddot{O} \mathbf{z}$}

There are two types of digital filters designed and used on digital signal processing systems: finite impulse response (FIR) and infinite impulse response (IIR). There are two approaches used during the design of FIR filters. The first of these is classical methods, while the other is optimization-based methods. The use of metaheuristic algorithms in optimization-based methods has been increasing in recent years, especially in order to realize more performance filter designs. In order to design a filter as close to the ideal as possible, in this study, FIR filter designs were carried out with metaheuristic algorithms using the multi-objective error approach, and the performance parameters of these designed filters were analyzed. FIR filter coefficients were optimized using Genetic Algorithm, Particle Swarm Optimization Algorithm, Artificial Bee Colony Algorithm, Black Widow Algorithm, Squirrel Search Algorithm, and Harmony Search Algorithm. When the obtained results and literature studies were compared, it was seen that there were significant improvements in the performance parameters of the FIR filter obtained with the proposed approach

Anahtar Kelimeler: Metasezgisel Algoritmalar, FIR Filtre Tasarımı, Sinyal İşleme, Optimizasyon.

\section{Performance Analysis in Optimization Based FIR Filter Designs}

\begin{abstract}
There are two types of digital filters designed and used on digital signal processing systems: finite impulse response (FIR) and infinite impulse response (IIR). There are two approaches used during the design of FIR filters. The first of these is classical methods, while the other is optimization-based methods. The use of metaheuristic algorithms in optimization-based methods has been increasing in recent years, especially in order to realize more performance filter designs. In order to design a filter as close to the ideal as possible, in this study, FIR filter designs were carried out with metaheuristic algorithms using the multi-objective error approach, and the performance parameters of these designed filters were analyzed. FIR filter coefficients were optimized using Genetic Algorithm, Particle Swarm Optimization Algorithm, Artificial Bee Colony Algorithm, Black Widow Algorithm, Squirrel Search Algorithm, and Harmony Search Algorithm. When the obtained results and literature studies were compared, it was seen that there were significant improvements in the performance parameters of the FIR filter obtained with the proposed approach.
\end{abstract}

Keywords: Metaheuristic Algorithms, FIR Filter Design, Signal Processing, Optimization.

\footnotetext{
*Sorumlu Yazar: Mehmet Fatih Karakaş, ORCID: 0000-0003-0233-6141, karakasmf@ gmail.com
} 


\section{Giriş}

Dijital Sinyal İşleme (DSP) sistemleri üzerinde tasarlanan basit yap1 bloklarına dijital süzgeçler denir (Litwin, 2000). Dijital süzgeçler bir sinyalin frekans ekseninin belirli bileşenlerini istenen çıkış sinyaline göre güçlendirmek, şekillendirmek için kullanılan sistemlerdir. Sonsuz dürtü yanıtlı (IIR) süzgeçler ve sonlu dürtü yanıtlı (FIR) süzgeçler olmak üzere iki ana süzgeç türü vardır. FIR süzgeçler her bir giriş dizisinin ağırlıklı toplamlarından oluşan lineer zamanla değişmeyen (LZD) sistemlerdir. Her zaman durağan olan bu sistemler lineer faz yanıtına sahiptir ve bu avantajları dolayısıyla geniş kullanım alanları bulunmaktadır. FIR süzgeçler gürültü azaltma, istenen frekansı iyileştirme ya da bastırma gibi hem sinyallere hem de görüntülere uygulanabilmektedir (Oppenheim, 1999). Dijital süzgeçler aynı zamanda elektrokardiyografi (EKG) gibi biyomedikal sinyaller üzerine gürültü azaltma, özellik çıkarımı gibi çeşitli analizleri gerçekleştirme amacıyla da uygulanmaktadır.

FIR süzgeç tasarımı konusunda 2 yaklaşım mevcuttur. Bunlardan ilki klasik yöntemler diğeri ise optimizasyon tabanlı yöntemlerdir. Klasik yöntemlerde pencereleme, frekans örneklemesi, ağırlıklı en küçük kareler veya eşdüzey yöntemi ile adaptif FIR süzgeç tasarımı mümkündür. Ancak bu yöntemlerde geçirme ve durdurma bandı dalgalanmaları, geçiş band 1 genişliği, geçirme ve durdurma bandı kesim frekansı gibi parametreler tam istenildiği gibi kontrol edilememektedir. Diğer bir yaklaşım olan optimizasyon tabanlı tasarımlarda bu parametreler bir hata fonksiyonu olarak tanımlanarak bu hata fonksiyonunun minimum yapılması amaçlanmaktadır. FIR süzgeç dizaynı konusunda optimizasyon tabanlı çeşitli uygulamalar bulunmaktadır (Parks \& Burrus, 1987; Proakis, 2001).

Optimizasyon tabanlı süzgeç tasarımlarında çeşitli yaklaşımlar ve yöntemler kullanılmaktadır. Literatürde optimizasyon tabanlı süzgeç tasarımı için; Genetik Algoritma (GA) (N. Karaboga \& Cetinkaya, 2004; Kaya \& İnce, 2011; Najjarzadeh \& Ayatollahi, 2008; Zhang et al., 2003), Parçacık Sürü Optimizasyonu Algoritması PSO (Chen \& Luk, 2010; Gupta \& Mehra, 2011; Najjarzadeh \& Ayatollahi, 2008), Diferensiyel Gelişim Algoritması (DE) (N. Karaboga, 2005; N. Karaboga \& Cetinkaya, 2006; Reddy \& Sahoo, 2015), Yapay Ar1 Kolonisi Algoritması (ABC) (Bose et al., 2014; N. Karaboga, 2009; Karaboğa \& Çetinkaya, 2011; Latifoğlu, 2020; Latifoğlu, 2013), Harmoni Arama Algoritması (HA) (Manuel \& Elias, 2012; Saha et al., 2013), Sincap Arama Algoritmas1 (SSA) (Karakaş \& Latifoğlu, 2020; Nagasirisha \& Prasad, 2020) kullanılan çalışmalar mevcuttur. Ancak Karadul Örümceği Algoritması (BWO) için herhangi bir çalışma bulunmamaktadır. Ayrıca Kumar ve ark. 2021 yılında yaptığı "Dijital Filtre Tasarımı İçin Optimizasyon Algoritmalarının İncelenmesi ve Analizi" isimli araştırma çalışmasında bu algoritmalarla yapılmış filtre tasarımları incelenmiştir ( $\mathrm{S}$. Kumar \& others, 2021).

İdeal yapıdaki bir FIR süzgeç zaman ekseninde ileri yönlü fark denklemleri kullanılarak

$y[n]=\sum_{k=-\infty}^{\infty} b_{k} x[n-k]$ şeklinde ifade edilmektedir.

$\mathrm{Bu}$ denklemde $b_{k}$ FIR süzgeç katsayılarıdır. Bir LZD sistemin dürtü yanıtı $h[n]$, sistem girişine uygulanan $\delta[n]$ lerin toplamı şeklinde gösterilebilir ve ideal olmayan $M$. dereceden bir FIR süzgeç için

$h[n]=\sum_{k=0}^{M} b_{k} \delta[n-k]$

şeklinde tanımlanabilir.

$h[n]$ hesaplanarak elde edilen FIR süzgecin Z eksenindeki transfer fonksiyonu

$H[Z]=\sum_{k=0}^{M} b_{k} Z^{-k}$

şeklinde tanımlanır.

FIR süzgece ait olan $b_{k}$ katsayıları yukarıda bahsi geçen optimizasyon algoritmaları kullanılarak optimize edilecek parametreler olarak belirlenebilmektedir.

Gerçekleştirilen çalışmada optimizasyon tabanlı FIR süzgeç tasarlanmıştır. $\mathrm{Bu}$ amaç doğrultusunda Genetik Algoritma, Parçacık Sürü Optimizasyonu Algoritması, Diferansiyel Gelişim Algoritması, Yapay Arı Kolonisi Algoritması, Karadul Örümceği Algoritmas1, Sincap Arama Algoritmas1, Harmoni Arama Algoritması kullanarak $b_{k}$ katsayıları optimize edilmiştir. Optimizasyon işlemi sırasında amaç fonksiyonu çoklu parametreye dayalı olarak elde edilmiştir.

Özet olarak bu çalışma;

- FIR süzgeç tasarımında Karadul Örümceği Algoritmasının ilk defa kullanılıyor olması açısından,

- Yukarda belirtilen optimizasyon algoritmalarının tümünün FIR süzgeç tasarımında performansının test edilerek ilk defa karşılaştırılması açısından,

- Amaç fonksiyonunun çoklu performans parametresine bağlı olarak gerçekleştirilmesi açısından,

özgünlük içermektedir.

Makalenin organizasyonu şu şekildedir; 2 . bölüm materyal ve metoddan oluşmaktadır ve süzgeç tasarımı için kullanılan algoritmalar ile gerçekleştirilen işlem adımları kısaca açıklanmıştır. 3. bölümde süzgeç tasarımına ait performans sonuçları verilmiştir ve elde edilen bulgular tartışılmıştır.

\section{Materyal ve Metot}

$\mathrm{Bu}$ bölümde süzgeç tasarımı için kullanılan optimizasyon algoritmaları kısaca açıklanmıştır. Kullanılan hata fonksiyonlarının ve süzgeç performans parametrelerinin eldesi ortaya konulmuştur. Algoritmalara ilişkin kontrol parametrelerini belirlemek için literatürde bu algoritmalar ile yapılmış olan çalışmalar incelenmiştir. İncelenen çalışmalardaki kontrol parametreleri ufak değişiklikler göstermekte olup genel itibari ile standartlaşmıştır. $\mathrm{Bu}$ nedenle bu parametreler ve değişik değerlerdeki parametreler ile testler yapılarak en optimum 
parametreler belirlenmiştir. Buna göre belirlenen algoritma kontrol parametreleri Tablo 1-2-3-4-5-6-7'de verildiği üzeredir.

Tüm analizler Windows-10 işletim sistemine, $3 \mathrm{GHz}$ AMD Ryzen 5 4600H işlemci, $8 \mathrm{~GB} 3200 \mathrm{MHz}$ RAM ve 4 GB NVDIA GeForce GTX 1650 ekran kartı kullanan bir bilgisayar üzerinde MATLAB 2020b kullanılarak yapılmıştır.

\subsection{Genetik Algoritma}

Genetik algoritma (GA); stokastik arama sürecine dayanan bir optimizasyon tekniğidir. Darwin'in yaşayan canlıların doğal evrim süreçleri ilham alınarak tasarlanmıştır. Doğal seçilim ve üreme olmak üzere iki adet mekanizmadan oluşur bu optimizasyon tekniğinde en iyi bireylere ait özellikler genetik miras olarak sonraki nesle aktarılarak küresel en iyiye yaklaşım gerçekleştirilir. Tekrarlı üreme ile uygunluk değeri yüksek olan bireylerin hayatta kalması ve sayılarının artması, uygunluk değeri düşük olan bireylerin ise sayılarının azalarak kaybolması amaçlanır. Çaprazlama ile iki bireyden yeni iki birey elde edilir. Çaprazlama iyi bireyler kullanılarak daha iyi bireylerin elde edilmesi amacıyla yapılır. Mutasyon ile elde bulunan çözümlerin değiştirilerek yeni bireyler elde edilmesi amaçlanır. Mutasyon sayesinde yerel minimum değerlere takılmadan küresel bir arama gerçekleştirilmesi sağlanır (Holland \& others, 1992; Jarraya \& Bouri, 2012)

Genetik algoritmanın temel adımları aşağıdaki gibidir;

- Rastgele değerlerden oluşan N kromozomlu bir popülasyonun oluşturulmas1.

- Her kromozoma ait uygunluk değerlerinin hesaplanmas1.

- Durdurma kriterini kontrol et, durdurma kriteri sağlanana kadar aşağıdaki adımların tekrarlanması

- Bir çift ebeveyn kromozom seçilmesi.

- Çaprazlamanın yapılması.

- Mutasyonun yapilmasi

- Adim 2'ye geri dön.

$\mathrm{Bu}$ çalışmada süzgeç tasarımı aşamasında GA için parametrelerin seçimi deneysel olarak belirlenmiş ve Tablo 1'de bu parametreler verilmiştir.

Tablo 1 GA Parametreleri

\begin{tabular}{l|l} 
Parametreler & Değerler \\
\hline Çaprazlama Oranı & 0,650 \\
\hline Mutasyon Oranı & 0,100 \\
\hline Elit Birey Oranı & 0,250
\end{tabular}

\subsection{Parçacık Sürü Optimizasyonu Algoritması}

Parçacık Sürü Optimizasyonu (PSO); sürü halinde hareket eden canlıların yiyecek arama, güvenlik gibi genellikle rastgele sergiledikleri hareketleri taklit ederek optimum çözüme ulaşmayı hedefleyen bir algoritmadır. PSO'da; bireylerin yani parçacıkların kendi aralarında gerçekleştirmiş oldukları sosyal bilgi paylaşımını temel alarak bu parçacıkların sürü içerisinde bulunan en iyi parçacığa yaklaştırılması esas alınmaktadır. Parçacıklar eski konumlarının bilgisini kullanarak kendilerini sürü içerisindeki en iyi parçacığa doğru yönlendirir. $\mathrm{Bu}$ yaklaşma işlemi rastgele sürdürülür ve optimum çözüme ulaşılana kadar devam eder (Clerc \& Kennedy, 2002).

PSO algoritmasının temel adımları aşağıdaki gibidir;

- Bütün parçacıklar için başlangıç hız ve konum değerleri ile algoritma başlangıç parametrelerinin belirlenmesi.

- Bütün parçacıkların uygunluk değerlerini belirlenmesi.

- Yerel ve küresel en iyi çözümleri belirlenmesi.

- Bütün parçacıklar için; hız ve pozisyon değerlerinin güncellenmesi.

- Durdurma kriterini kontrol et, durdurma kriteri sağlanmiyorsa Adım 2'ye geri dön.

$\mathrm{Bu}$ çalışmada süzgeç tasarımı aşamasında PSO için parametrelerin seçimi deneysel olarak belirlenmiş ve Tablo 2'de bu parametreler verilmiştir.

Tablo 2 PSO Parametreleri

\begin{tabular}{l|l} 
Parametreler & Değerler \\
\hline Çaprazlama Oranı & 0,650 \\
\hline Mutasyon Oranı & 0,100 \\
\hline Elit Birey Oranı & 0,250
\end{tabular}

\subsection{Diferansiyel Gelişim Algoritması}

Diferansiyel gelişim algoritması (DE); çalışma prensibi bakımında genetik algoritmaya oldukça benzeyen popülasyon tabanlı bir optimizasyon algoritmasıdır. Sürekli değişkenli problemlerin çözümüne yönelik olarak geliştirilen DE, GA'da olduğu gibi popülasyona dayalı olarak çalışmak yerine tek tek kromozomlar üzerinde mutasyon ve çaprazlama operatörlerinin işleme geçirilmesi ile yeni bireyleri elde eder (Storn \& Price, 1997).

DE algoritmasının temel adımları aşağıdaki gibidir:

- Başlangıç popülasyonunun oluşturulması.

- Uygunluk değerlerinin belirlenmesi ve değerlendirilmesi.

- Durdurma kriterini kontrol et, durdurma kriteri sağlanana kadar aşağıdaki adımların tekrarlanması.

$$
\begin{array}{ll}
\circ & \text { Mutasyon } \\
\circ & \text { Rekombinasyon } \\
\circ & \text { Seleksiyon }
\end{array}
$$

- $\quad$ Adım 2'ye geri dön

$\mathrm{Bu}$ çalışmada süzgeç tasarımı aşamasında DE için aşağıdaki tabloda belirtilen parametreler kullanılmıştır. Parametrelerin seçimi deneysel olarak belirlenmiş ve Tablo 3'de bu parametreler verilmiştir.

Tablo 3 DE Parametreleri

\begin{tabular}{l|l} 
Parametreler & Değerler \\
\hline Beta Min & 0,200 \\
\hline Beta Max & 0,800 \\
\hline Çaprazlama Olasılığı & 0,200
\end{tabular}




\subsection{Yapay Arı Kolonisi Algoritması}

Yapay Arı Kolonisi (ABC); bal arılarının yiyecek arama davranışı esnasında arıların kendi aralarında iletişime geçerek en iyi yiyeceğin bulunduğu yani optimum çözümün bulunduğu konum bilgisinin birbirleri arasında paylaşılması ve bu konum bilgisinin güncellenmesi esasına dayanmaktadır. Her arı bir yiyecek kaynağına konumlanarak bu kaynağın komşularının çözümleri araştırılır. Bu algoritmada üç çeşit arı bulunmaktadır ve bu arı türlerinin davranışları birbirinden farklıdır. İşçi arılar, hafıza elemanı olarak görev alarak hafizada tuttuğu kaynağın komşuluklarında bulunan çözümleri araştırarak bulduğu daha iyi çözümlerle hafizasını günceller. Gözcü arılar; bir hafiza elemanına sahip değillerdir. İşçi arılardan elde edilen bilgiye göre uygunluk değeri yüksek olma ihtimali olan bir kaynağı yiyecek kaynağı olarak seçer. Gözcü arı seçilen bu kaynağın komşuluklarını araştırarak daha iyi olan çözümlerle kaynağın konum bilgisini günceller. Bir kaynağın araştırılma sayısının bir limit değerine ulaşması bu kaynaktaki yiyeceğin tükendiği anlamına gelir. Kaynakta bulunan arı araştırmayı bırakarak kaşif arı olur. Bu kaşif arı araştırma yapmak üzere rastgele yeni bir kaynak seçer. $\mathrm{Bu}$ rastgele kaynak seçimi yerel minimumlara algoritmanın takılmasını engellemek içindir (D. Karaboga, 2005).

$\mathrm{ABC}$ algoritmasının temel adımları aşağıdaki gibidir:

- Başlangıç yiyecek kaynaklarının rassal bir şekilde üretilmesi.

- İşçi arıların bu kaynaklara yine rassal olarak yönlendirilmesi.

- Olasılıksal seçimde kullanılmak üzere bulunan yeni çözüm için olasılık değerinin hesaplanması.

- Hesaplanan olasılık değerine göre gözcü arıların yiyecek kaynağına gönderilmesi.

- Nektarı biten kaynağın bırakılması ve kaşif arı üretimi.

$\mathrm{Bu}$ çalışmada süzgeç tasarımı aşamasında $\mathrm{ABC}$ için parametrelerin seçimi deneysel olarak belirlenmiş ve Tablo 4'de bu parametreler verilmiştir.

\section{Tablo 4 ABC Parametreleri}

\begin{tabular}{l|l} 
Parametreler & Değerler \\
\hline Terketme Limit Oranı & 0,600 \\
\hline Hızlandırma Katsayısı & 1,000
\end{tabular}

\subsection{Karadul Örümceği Optimizasyon Algoritması}

Karadul Örümcek Algoritması (BWO); karadul örümceklerinin üreme ve sonrasında ortaya çıkan yeni yavruların birbirleri arasındaki hayatta kalma ilişkilerini taklit eden popülasyon tabanlı bir algoritmadır. Karadul örümceklerinin dişi bireyleri üreme sonrasında erkek bireyleri yer. Daha sonrasında ortaya çıkan yeni yavrular arasında da yamyamlık gözükür. $\mathrm{Bu}$ yamyamlık neticesinde yavru karadul örümcekleri arasında güçlü olanlar hayatta kalarak güçsüz olanlar yok olur. Yavrular yeterince büyüdükten sonra annelerine de yamyamlık yapma ihtimalleri bulunmaktadır. Genetik algoritmaya çaprazlama, mutasyon gibi parametreler konusunda oldukça benzer olan bu yeni nesil algoritmada ekstra olarak yamyamlık durumu bulunmaktadir (Hayyolalam \& Pourhaji Kazem, 2020).
BWO algoritmasının temel adımları aşağıdaki gibidir:

- Başlangıç popülasyonunun rastgele oluşturulması.

- Bütün bireylere ait uygunluk değerlerinin belirlenmesi ve değerlendirilmesi.

- Durdurma kriterini kontrol et, durdurma kriteri sağlanana kadar aşağıdaki adımların tekrarlanması.

○ Bir çift ebeveyn seçilmesi.

- Çaprazlamanın yapılması.

- Yamyamlık

- Mutasyon

○ Popülasyonun güncellenmesi

- Adim 2'ye geri dön.

$\mathrm{Bu}$ çalışmada süzgeç tasarımı aşamasında BWO için parametrelerin seçimi deneysel olarak belirlenmiş ve Tablo 5'de bu parametreler verilmiştir.

\section{Tablo 5 BWO Parametreleri}

\begin{tabular}{l|l} 
Parametreler & Değerler \\
\hline Çaprazlama Oranı & 0,800 \\
\hline Mutasyon Oranı & 0,400 \\
\hline Yamyamlık Oranı & 0,500
\end{tabular}

\subsection{Sincap Arama Algoritması}

Sincap arama algoritması (SSA); uçan sincapların yiyecek arama ve hayatta kalma döngülerini taklit eden bir algoritmadır. Burada uçan sincap olarak adlandırılan keseliler süzülme hareketi yaparak yaşadıkları ağaçlar arasında hızlı bir şekilde pozisyon değiştirmektedirler. Bu pozisyon değiştirme işlemi yiyecek kaynağı açısından sıradan olan meşe palamudu ağaçları ile normal ağaçlardan yiyecek kaynağı açısından bol olan Kuzey Amerika Cevizi ağacına doğrudur. $\mathrm{Bu}$ pozisyon değiştirme işlemi mevsim durumuna göre ve ortamda bulunan yırtıc1 olasılığından etkilenir. Eğer yırtıcı olasılığı belirlenen değerden yüksek ise hareket eden sincap ölür ve yeni bir sincap popülasyona dahil edilir. Mevsim durumu yaz iken hareket halinde olan sincaplar mevsim durumu kış olduğundan yani durdurma kriteri sağlandığında yeterince yiyecek toplamış ve küresel optimuma yaklaşmış var sayılırlar (Jain et al., 2019).

SSA algoritmasının temel adımları aşağıdaki gibidir:

- Rastgele konumlarda sincapların oluşturulması.

- Sincapların uygunluk değerlerinin belirlenmesi ve değerlendirilmesi.

- Uygunluk değerlerine göre sincapların sıralanması ve bu sincaplar arasından rastgele seçimlerin yapılması.

- En iyi uygunluk değerine sahip olan sincap Amerikan ceviz ağacında varsayılır.

○ Sonraki en iyi uygunluk değerine sahip 3 sincap meşe palamudu ağacında varsayılır.

- Kalan sincaplar normal ağaçta var sayılır

- Sincaplar harekete geçmesi. Sincap hareketi 3 durumda olabilir.

○ Meşe palamudu ağacındaki sincaplar ortamda bulunan yırtıcı olasılığı göz önüne alınarak Amerikan ceviz ağacına doğru hareket edebilir. 
- Normal ağaçlarda bulunan sincaplar ortamda bulunan yırtıcı olasılığı göz önüne alınarak Amerikan ceviz ağacına doğru hareket edebilir.

- Normal ağaçlarda bulunan sincaplar ortamda bulunan yırtıcı olasılığı göz önüne alınarak meşe palamudu ağacına doğru hareket edebilir.

- Mevsim durumunun kontrol edilmesi. Eğer kış mevsimi ise sincaplar rastgele konumlarda tekrar oluşturulur, değilse algoritma devam eder.

- Adim 2' ye geri dön.

$\mathrm{Bu}$ çalışmada süzgeç tasarımı aşamasında SSA için parametrelerin seçimi deneysel olarak belirlenmiş ve Tablo 6'da bu parametreler verilmiştir.

\section{Tablo 6 SSA Parametreleri}

\begin{tabular}{l|l} 
Parametreler & Değerler \\
\hline Yırtıcı Olasılığı & 0,100 \\
\hline Süzülme Katsayısı & 1,900 \\
\hline Meşe Palamudu Oranı & 0,600
\end{tabular}

\subsection{Harmoni Arama Algoritması}

Harmoni Arama Algoritması (HA); müzik tabanlı bir meta sezgisel algoritma olarak optimizasyon problemlerini çözmek amaçlı geliştirilmiştir (Geem et al., 2001). HA'da her müzisyen, daha iyi parçalar çalmak amacıyla amacına uygun olan iyi notları yani yerel çözümleri hafızasında tutar. Bu algoritmada bir müzisyen üç farklı şekilde en iyi harmoniyi, küresel çözümü, müzik parçasını bulur;

- Hafizasında tuttuğu be iyi olduğunu düşündüğü bir notayı çalarak. (Ezberleme)

- Hafızasındaki bu notayı iyileştirerek. (İyileştirme)

- Rastgele notalar üreterek. (Geliştirme)

HA algoritmasının temel adımları aşağıdaki gibidir:

- Başlangıç parametrelerini ve rastgele notaları oluştur.

- Esinlenme ile yeni bir çözüm oluştur.

- Çözümleri hesapla ve değerlendir.

- Sonlandırma kriterini kontrol et. Sağlanıyorsa algoritmayı durdur. Sağlanmıyorsa Adım 2'ye geri dön.

$\mathrm{Bu}$ çalışmada süzgeç tasarımı aşamasında HA için parametrelerin seçimi deneysel olarak belirlenmiş ve Tablo 7'de bu parametreler verilmiştir.

Tablo 7 HA Parametreleri

\begin{tabular}{l|l} 
Parametreler & Değerler \\
\hline Yeni Harmoni Sayısı & 20,000 \\
\hline Harmoni Hafızası Önem Oranı & 0,900 \\
\hline Adım Ayarlama Oranı & 0,100 \\
\hline Perde Genişliği Azaltma Oranı & 0,995
\end{tabular}

\subsection{Hata Fonksiyonunun Tanımlanması}

$\mathrm{Bu}$ çalışmada FIR süzgece ait $b_{k}$ katsayıları, optimize edilecek parametreler olarak belirlenmiştir. $b_{k}$ katsayılarının değerlerine göre ideal olmayan FIR süzgecin performans parametreleri belirlenmektedir. $\mathrm{Bu}$ parametreler Şekil 1'de gösterilmektedir.

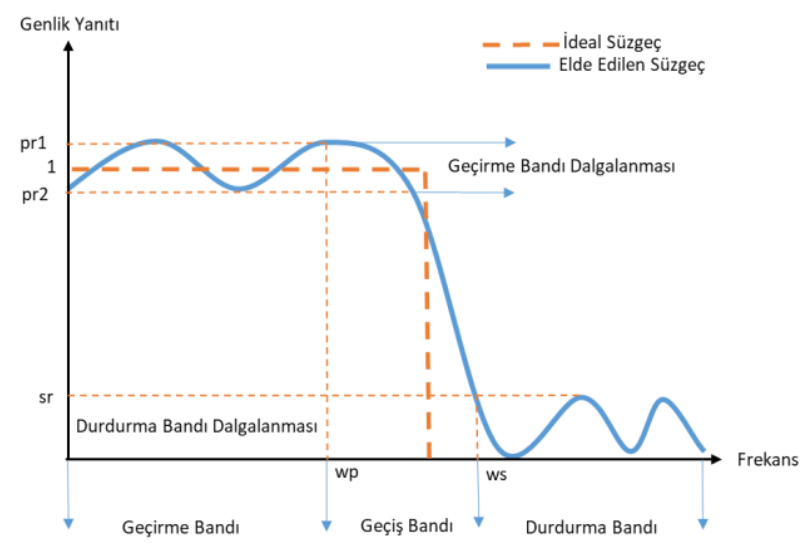

Şekil 1. FIR Filtre Parametreleri

İdeal olmayan FIR süzgece ait performans parametreleri aşağıda verilmektedir.

- Geçirme ve durdurma band1 dalgalanmaları (pr1, pr2, sr)

$\operatorname{pr} 1=\max \left\{\operatorname{Peaks}\left(H\left(e^{j w}\right)\right)\right\} w \leq w_{p}$

$\operatorname{pr} 2=\min \left\{\operatorname{Peaks}\left(-H\left(e^{j w}\right)\right)\right\} w \leq w_{p}$

$s r=\max \left\{\operatorname{Peaks}\left(-H\left(e^{j w}\right)\right)\right\} w \geq w_{s}$

- Geçirme, geçiş ve durdurma bandı hataları (Ep, Et, Es)

$E p=\frac{1}{\pi} \sum_{0}^{w p}\left[H\left(e^{j 0}\right)-H\left(e^{j w}\right)\right]^{2}$

$E t=\left[\left(H\left(e^{j \frac{1}{\pi}}\right)-\left(0.707 H\left(e^{j 0}\right)\right]^{2}\right.\right.$

$E s=\frac{1}{\pi} \sum_{w s}^{\pi}\left[H\left(e^{j w}\right]^{2}\right.$

- İdeal süzgeç ile elde edilen süzgeç arasındaki korelasyon

$c c=$ korelasyon $\left\{H\left(e^{j w}\right), H_{\text {istenen }}\right\}$

İdeal süzgeç için yukarıda tanımlanan bütün parametrelerin sifir olmas1 gerekmektedir. $\mathrm{Bu}$ parametreler belirlenen algoritmalar için hata vektörü olarak belirlenmiştir ve hata vektörü ile hata fonksiyonu aşağıdaki gibi tanımlanmıştır.

$\operatorname{Hata}(X)=[p r 1, p r 2, s r, E p, E t, E s, c c]$

ToplamHata $=\sum_{i=1}^{7} X_{i}$

Süzgeç yapısı oluşturulurken; ideale yakın olması açısından geçirme bandı frekansı (wp) olarak normalize frekans $0.49 \mathrm{rad} / \mathrm{pi}$ durdurma band1 frekansı (ws) olarak normalize frekans 0.51 $\mathrm{rad} /$ pi belirlenmiştir. İdeale yakın süzgeç yapısı oluşturulurken aşağıdaki kod bloğu kullanılmıştır; 
function hd $=$ HDesired(wp,ws)

$\mathrm{wd}=1 / 1024: 1 / 1024: 1$;

hx1 $=$ ones $(1$, length $($ find $($ wd $<w p)))$;

$\mathrm{hx} 2=$ linspace $(1,0$,length $($ find $(\mathrm{wp}<=\mathrm{wd} \& \mathrm{wd}<=\mathrm{ws}))$ );

$\mathrm{hx} 3=$ zeros $(1$,length $($ find $(\mathrm{wd}>\mathrm{ws})))$;

$\mathrm{hd}=[\mathrm{hx} 1, \mathrm{hx} 2, \mathrm{hx} 3]$;

end

İdeale yakın süzgece ait frekans yanıtı Şekil 2'deki gibi elde edilmiştir.

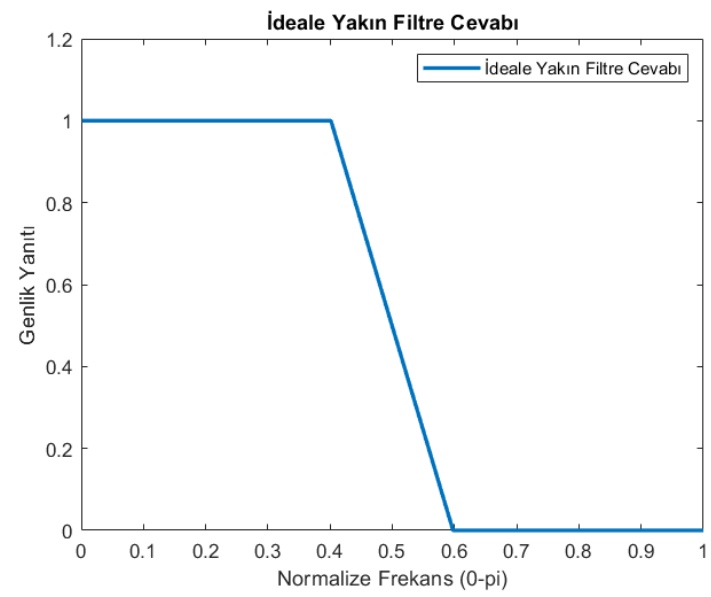

Şekil 2. Ideale Yakın Süzgeç Frekans Yanıtı

Yukarıda bahsi geçen bütün algoritmalar için süzgeç katsayılarının hesaplanması için kullanılan parametreler Tablo 8 'de verilmiştir.

Tablo 8 Algoritma Genel Parametreleri

\begin{tabular}{l|l} 
Parametreler & Değerler \\
\hline Popülasyon & 100 \\
\hline İterasyon Sayısı & 2500 \\
\hline wp & 0,49 \\
\hline ws & 0,51
\end{tabular}

Her bir algoritma ile elde edilen farklı derecelerdeki süzgeçler için performans parametreleri de incelenmiştir. Kullanılan performans parametreleri aşağıda verildiği üzeredir.

- Geçirme bandı maksimum dalgalanma miktarı

$\operatorname{pr} 1=\max \left\{\operatorname{Peaks}\left(H\left(e^{j w}\right)\right)\right\}$

$w \leq w_{p}$

- Durdurma bandı minimum dalgalanma miktarı

$\operatorname{pr} 2=\min \left\{\operatorname{Peaks}\left(-H\left(e^{j w}\right)\right)\right\}$

$w \leq w_{p}$

- Desibel cinsinden durdurma bandı zayıflaması

$A s=-20 \log \left(\max \left\{\operatorname{Peaks}\left(-H\left(e^{j w}\right)\right)\right\} w \geq w_{s}\right)$

- Geçirme bandı toplam hatası
$E p=\frac{1}{\pi} \sum_{0}^{w p}\left[H\left(e^{j 0}\right)-H\left(e^{j w}\right)\right]^{2}$

- Durdurma bandi toplam hatası

$E s=\frac{1}{\pi} \sum_{w s}^{\pi}\left[H\left(e^{j w}\right)\right]^{2}$

- Geçiş bandı toplam hatası

$E t=\left[\left(H\left(e^{j \frac{1}{\pi}}\right)-\left(0.707 H\left(e^{j 0}\right)\right]^{2}\right.\right.$

- Toplam iterasyon süresi (total iter time)

\section{Sonuçlar}

Bahsi geçen algoritmalar ve hata fonksiyonu kullanılarak elde edilen FIR süzgeçlere ait $b_{k}$ katsayıları ve bu katsayılar ile elde edilmiş frekans yanıtları Tablo 10-11-12-13-14-15' de verilmiştir. Elde edilen tüm süzgeçler için ayrıca performans parametreleri karşılaştırmaları Tablo 16' de verilmiştir. Tablo 17 'de tüm performans parametreleri için en iyi sonucu veren algoritma belirtilmiştir.

Örneğin tasarlanan 5. dereceden FIR süzgecin performans parametreleri incelendiğinde SSA algoritması ile optimize edilen süzgeç katsayılarına ait frekans yanıtının geçirme bandı maksimum dalgalanması, durdurma bandı toplam hatası, geçiş bandı hatası diğer algoritmalara göre daha iyi sonuç vermiştir.

30. dereceden FIR süzgecin performans parametreleri incelendiğinde ise PSO algoritması ile optimize edilen süzgeç katsayılarına ait frekans yanıtının geçirme bandı minimum dalgalanması, geçirme band1 toplam hatası ve durdurma band toplam hatası diğer algoritmalara göre daha iyi sonuç vermiştir.

Tasarlanan süzgecin performansı klasik yöntemlerden olan equiripple FIR süzgeç yapısı ile karşılaştırılmıştır. Bu amaç doğrultusunda tüm süzgeç dereceleri için optimizasyon algoritmaları ile elde edilen frekans yanitları ve equiripple yöntemi ile elde edilen frekans yanıtları Şekil 3-4-5-6-7-8'de görülmektedir. Şekiller incelendiğinde; önerilen yöntemin geçirme bandı dalgalanmaları, durdurma bandı dalgalanmaları ve bunlara ait performans parametrelerinin daha üstün olduğu açıkça görülmektedir.

Literatür çalışmalarda hata fonksiyonunun eldesi aşamasında genellikle geçirme ve durdurma bandı hataları toplamı (Aggarwal et al., 2016; Saha et al., 2014; Shao et al., 2017) ya da istenilen frekans yanitı ile tasarlanan frekans yanitı arasındaki farkın ortalama karesel hatası kullanılmıştır (N. Karaboga \& Cetinkaya, 2006). Önerilen bu çalışmada; çoklu hata parametreleri göz önünde bulundurularak çok amaçlı hata yaklaşımı sergilenmiştir. Literatürdeki çalışmalardan PSO (Sarangi et al., 2020), ABC (A. Kumar et al., 2017), GA ve DE (N. Karaboga \& Cetinkaya, 2006) için karşılaştırma yapabilme amacıyla $0-0.4 \pi$ geçirme bandına sahip, $0.6 \pi-\pi$ durdurma bandına sahip 20. dereceden FIR süzgeç tasarlanmıştır. Tasarıma ait karşılaştırma tablosu Tablo 9'da verilmiştir. Tablo 9'da koyu olarak verilen değerler diğer metoda göre daha iyi sonuçlar veren değerlerdir. Tablo 9 incelendiğinde; önerilen metodun PSO için pr1,pr2,sr,AS,Ep,Et için daha iyi sonuçlar verdiği, ABC için; pr1,pr2 ve Et için daha iyi sonuçlar verdiği, GA için sr, AS, Et, Es için daha iyi sonuçlar verdiği ancak DE için herhangi bir iyileştirme yapılmadığı görülmektedir. 


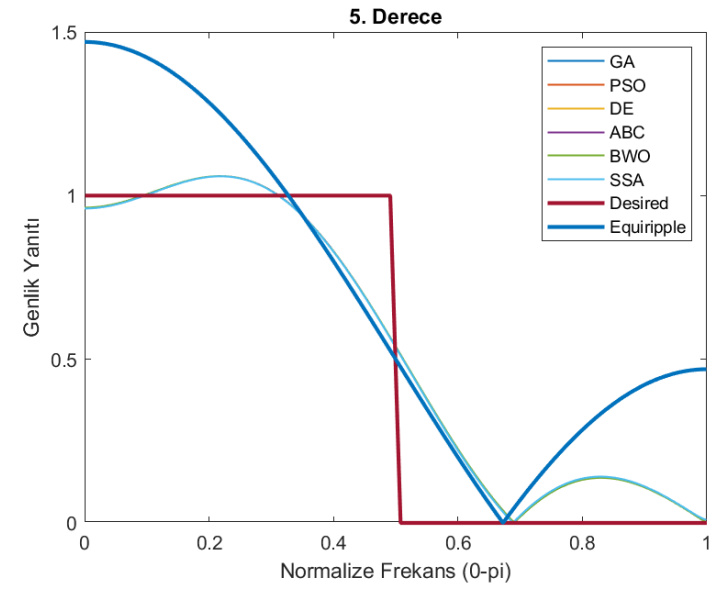

Şekil 3 5. Dereceden Süzgeç Frekans Yanıtı

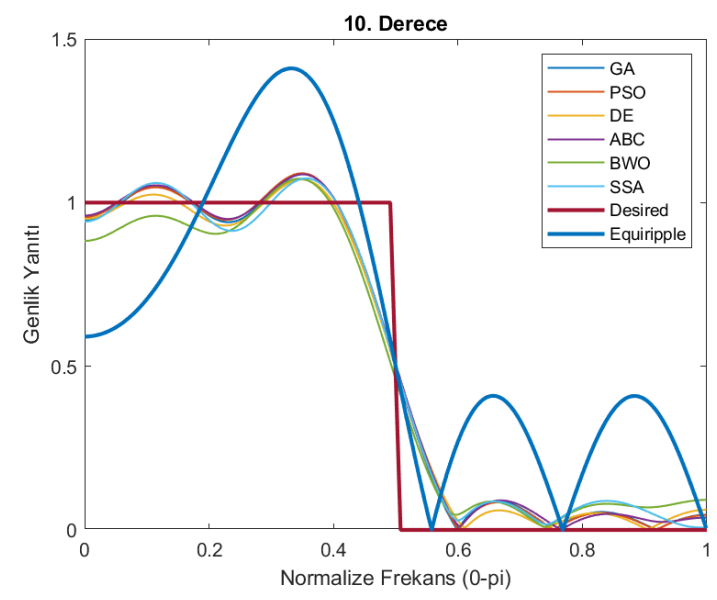

Şekil 4 10. Dereceden Süzgeç Frekans Yanıtı

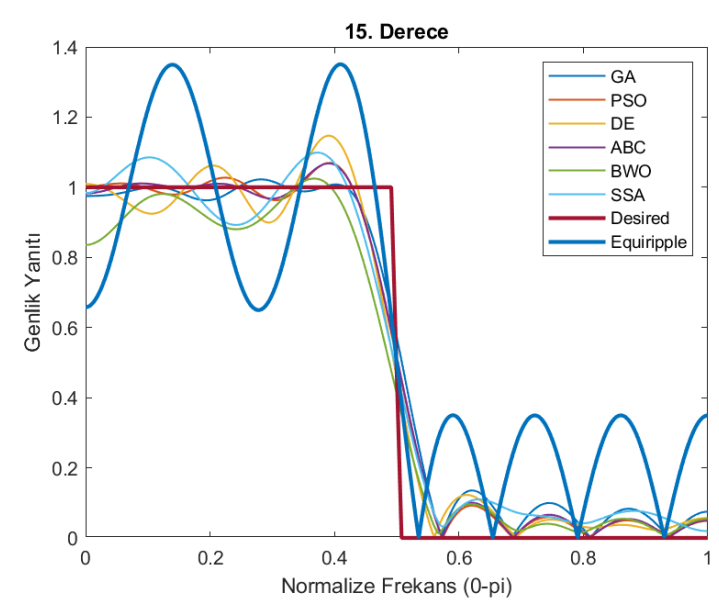

Şekil 5 15. Dereceden Süzgeç Frekans Yanıtı

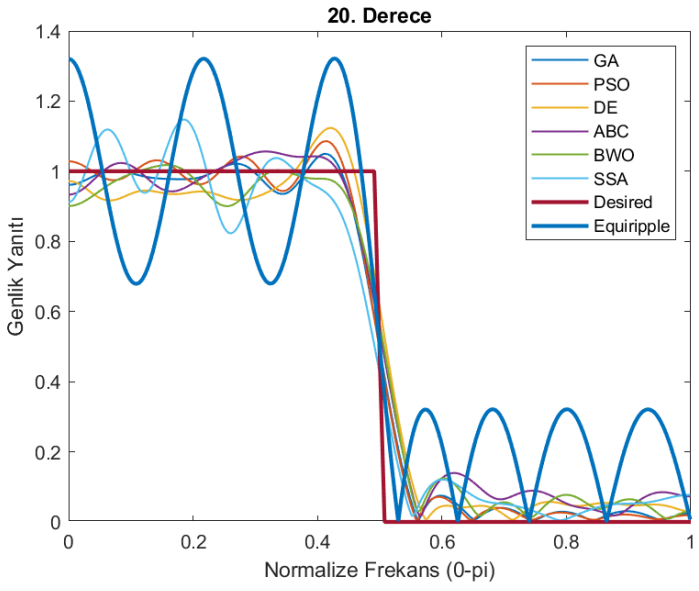

Şekil 6 20. Dereceden Süzgeç Frekans Yanıtı

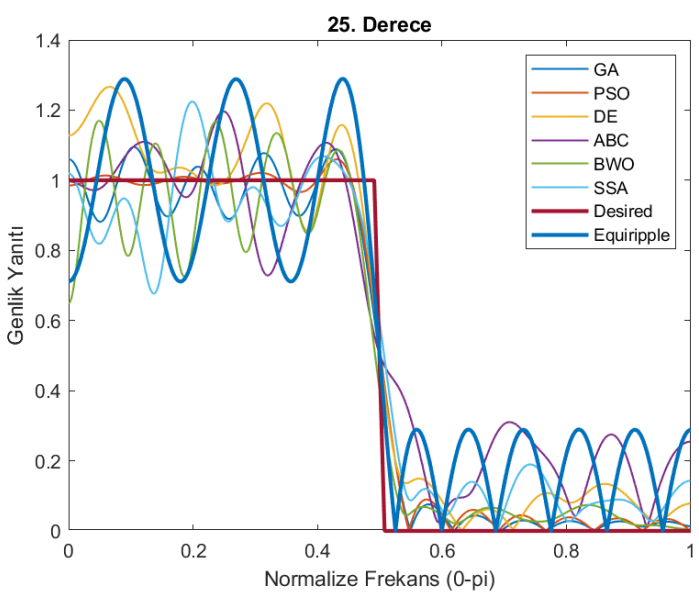

Şekil 7 25. Dereceden Süzgeç Frekans Yanıtı

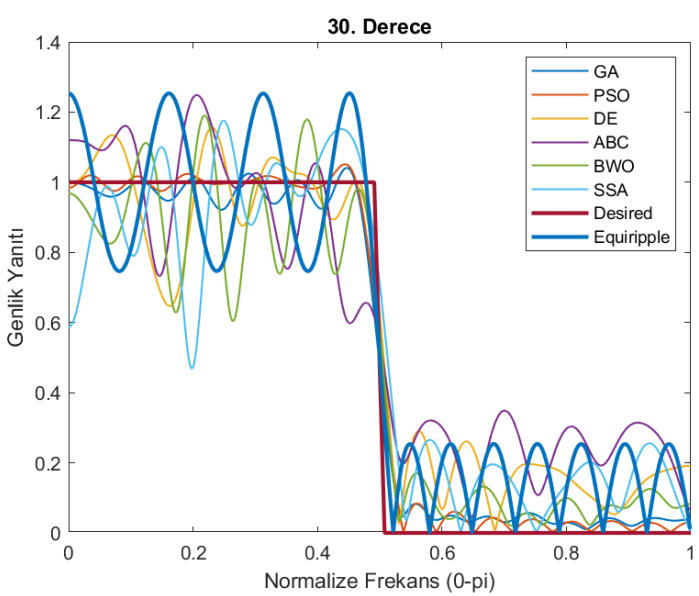

Şekil 8. 30. Dereceden Süzgeç Frekans Yanıtı 
European Journal of Science and Technology

Tablo 9. 20. Dereceden Literatür Karşılaştırma

\begin{tabular}{c|l|l|l|l|l|l|l|l} 
& \multicolumn{2}{|c|}{ PSO } & \multicolumn{2}{c|}{ ABC } & \multicolumn{2}{c|}{ GA } & \multicolumn{2}{c}{ DE } \\
\hline & Literatür & Önerilen & Literatür & Önerilen & Literatür & Önerilen & Literatür & Önerilen \\
\hline Pr1 & 0,01818 & $\mathbf{0 , 0 0 6 3 1}$ & 0,22547 & $\mathbf{0 , 1 2 4 0 5}$ & $\mathbf{0 , 0 3 9 1 0}$ & 0,04518 & $\mathbf{0 , 0 3 3 8 5}$ & 0,14076 \\
\hline Pr2 & 0,04481 & $\mathbf{0 , 0 0 0 3 9}$ & 0,31120 & $\mathbf{0 , 0 6 0 8 8}$ & $\mathbf{0 , 0 3 4 4 5}$ & 0,03656 & $\mathbf{0 , 0 2 8 0 9}$ & 0,04026 \\
\hline Sr & 0,07781 & $\mathbf{0 , 0 0 9 5 4}$ & $\mathbf{0 , 1 1 3 8 4}$ & 0,23751 & 0,05326 & $\mathbf{0 , 0 3 1 4 3}$ & $\mathbf{0 , 0 9 6 0 4}$ & 0,16331 \\
\hline AS & 51,07025 & $\mathbf{9 3 , 0 4 5 5 6}$ & $\mathbf{4 3 , 4 5 9 7 0}$ & 28,75051 & 58,65271 & $\mathbf{6 9 , 2 0 0 6 2}$ & $\mathbf{4 6 , 8 5 9 4 6}$ & 36,24192 \\
\hline Ep & 0,96522 & $\mathbf{0 , 0 3 2 1 7}$ & $\mathbf{1 2 , 7 2 6 6 9}$ & 2,75524 & $\mathbf{0 , 5 1 0 8 5}$ & $\mathbf{0 , 5 8 8 5 1}$ & $\mathbf{0 , 3 9 5 3 6}$ & 1,76307 \\
\hline Et & 0,46000 & $\mathbf{0 , 0 2 9 7 8}$ & $\mathbf{2 , 2 2 0 4 8}$ & $\mathbf{1 5 , 9 5 8 3 3}$ & 0,52149 & $\mathbf{0 , 1 9 0 2 9}$ & $\mathbf{0 , 6 3 3 4 2}$ & 5,55188 \\
\hline Es & $\mathbf{0 , 0 5 4 6 0}$ & 0,08299 & $\mathbf{0 , 0 3 2 9 4}$ & 0,13967 & 0,07597 & $\mathbf{0 , 0 6 6 0 8}$ & 0,07801 & $\mathbf{0 , 0 7 2 4 5}$
\end{tabular}

Tablo 10. 5. Dereceden FIR Filtre Katsayllarl

\begin{tabular}{l|l|l|l|l|l|l|l}
$b_{k}$ & GA & PSO & DE & ABC & BWO & SSA & HA \\
\hline $\mathbf{1}$ & 0,3037761879 & $-0,1496075077$ & $-0,1500752791$ & 0,1500752025 & 0,3057104147 & $-0,3004822095$ & 0,3036897493 \\
\hline $\mathbf{2}$ & 0,4955602446 & $-0,0140320052$ & $-0,0147057873$ & 0,0147056712 & 0,4967495743 & $-0,4954656753$ & 0,4955986739 \\
\hline $\mathbf{3}$ & 0,3273919742 & 0,3274267867 & 0,3269526997 & $-0,3269530970$ & 0,3247288871 & $-0,3277665761$ & 0,3274941770 \\
\hline $\mathbf{4}$ & $-0,0140472380$ & 0,4956051022 & 0,4956064432 & $-0,4956065143$ & $-0,0155115305$ & 0,0099528304 & $-0,0139672896$ \\
\hline $\mathbf{5}$ & $-0,1495932530$ & 0,3037539479 & 0,3040232559 & $-0,3040229455$ & $-0,1483323672$ & 0,1529653146 & $-0,1496563594$
\end{tabular}

Tablo 11. 10. Dereceden FIR Filtre Katsayllarl

\begin{tabular}{c|c|c|c|c|c|c|c}
$b_{k}$ & $\mathbf{G A}$ & $\mathbf{P S O}$ & $\mathbf{D E}$ & $\mathbf{A B C}$ & BWO & SSA & HA \\
\hline $\mathbf{1}$ & 0,1059420541 & $-0,0715304257$ & 0,0710026991 & $-0,1723054067$ & 0,1074713944 & $-0,0684354385$ & 0,0843801962 \\
\hline $\mathbf{2}$ & 0,1265393960 & $-0,0340302124$ & 0,0261703736 & $-0,4366283314$ & 0,1937495733 & $-0,0560327401$ & 0,0112206201 \\
\hline $\mathbf{3}$ & 0,0228429004 & 0,0859806980 & $-0,0867244435$ & $-0,4376442447$ & 0,0302619832 & 0,0681358061 & $-0,2773930770$ \\
\hline $\mathbf{4}$ & 0,0132904979 & 0,0727848515 & $-0,0723600853$ & $-0,1329407058$ & $-0,2912659712$ & 0,0794107484 & $-0,4927842082$ \\
\hline $\mathbf{5}$ & 0,2375636065 & $-0,1051542919$ & 0,1098809817 & 0,1486432239 & $-0,4497485571$ & $-0,0583922151$ & $-0,3512668543$ \\
\hline $\mathbf{6}$ & 0,4554111197 & $-0,1594938383$ & 0,1560244943 & 0,1229617009 & $-0,2771372590$ & $-0,1677013562$ & $-0,0220303738$ \\
\hline $\mathbf{7}$ & 0,3470392084 & 0,0987177095 & $-0,1128901929$ & $-0,0649485266$ & $-0,0002760014$ & 0,0587251774 & 0,1239403603 \\
\hline $\mathbf{8}$ & $-0,0033794119$ & 0,4212087067 & $-0,4288881919$ & $-0,0922514025$ & 0,0169712247 & 0,3837523713 & 0,0066356237 \\
\hline $\mathbf{9}$ & $-0,2178989531$ & 0,4472563154 & $-0,4255633900$ & 0,0271878883 & $-0,0832909369$ & 0,4672414187 & $-0,0976213201$ \\
\hline $\mathbf{1 0}$ & $-0,1427698675$ & 0,2003007130 & $-0,1868562991$ & 0,0775144129 & $-0,1298126536$ & 0,2350161403 & $-0,0425467122$
\end{tabular}

Tablo 12. 15. Dereceden FIR Filtre Katsayllart

\begin{tabular}{|c|l|l|l|l|l|l|l|}
\hline$b_{k}$ & \multicolumn{1}{|c|}{ GA } & \multicolumn{1}{|c|}{ PSO } & \multicolumn{1}{|c|}{ DE } & \multicolumn{1}{|c|}{ ABC } & \multicolumn{1}{|c|}{ BWO } & SSA & HA \\
\hline $\mathbf{1}$ & 0,0618276230 & 0,00818888844 & $-0,0775532498$ & 0,0998385796 & 0,0531892843 & 0,0476627442 & $-0,0481737536$ \\
\hline $\mathbf{2}$ & $-0,0298890396$ & $-0,0901928010$ & $-0,0702607190$ & 0,0860231085 & 0,0217074937 & 0,0159739111 & 0,0007580106 \\
\hline $\mathbf{3}$ & $-0,1263592588$ & $-0,1260753648$ & 0,0676700241 & $-0,0812504248$ & $-0,0475429827$ & $-0,0446992121$ & 0,0628742617 \\
\hline $\mathbf{4}$ & $-0,0344492117$ & 0,0253632991 & 0,1347840176 & $-0,1579572196$ & 0,0056724223 & $-0,0200387880$ & 0,0162005469 \\
\hline $\mathbf{5}$ & 0,1647776161 & 0,1879467347 & 0,0778844016 & 0,0679489251 & 0,1568277615 & 0,1446961973 & $-0,0647093572$ \\
\hline $\mathbf{6}$ & 0,1660086188 & 0,0667543729 & 0,0757924396 & 0,4018102734 & 0,1268618390 & 0,2078426215 & $-0,0113857737$ \\
\hline $\mathbf{7}$ & $-0,0980368936$ & $-0,2811654143$ & 0,2543446508 & 0,4615915055 & $-0,1504754702$ & $-0,0815972239$ & 0,1060260031 \\
\hline $\mathbf{8}$ & $-0,2841920536$ & $-0,4703127872$ & 0,4263148668 & 0,2144835222 & $-0,4121852115$ & $-0,3805387829$ & 0,0229438351 \\
\hline $\mathbf{9}$ & $-0,1306520840$ & $-0,3179855192$ & 0,2903512994 & $-0,0090190800$ & $-0,3878660202$ & $-0,4483133942$ & $-0,2955469555$ \\
\hline $\mathbf{1 0}$ & 0,1800336512 & $-0,0733721311$ & $-0,0421560098$ & $-0,0147840973$ & $-0,1300876105$ & $-0,2101618925$ & $-0,4983516593$ \\
\hline $\mathbf{1 1}$ & 0,3186585211 & $-0,0080272692$ & $-0,2556475398$ & 0,0423809795 & 0,0312488166 & $-0,0095639551$ & $-0,3424797044$ \\
\hline $\mathbf{1 2}$ & 0,2589557456 & $-0,0553224417$ & $-0,1188974175$ & $-0,0067314547$ & $-0,0144337875$ & $-0,0384325078$ & $-0,0233969212$ \\
\hline $\mathbf{1 3}$ & 0,1957801909 & $-0,0216396252$ & 0,0936154434 & $-0,0835886260$ & $-0,0705201258$ & $-0,1229641350$ & 0,0991764513 \\
\hline $\mathbf{1 4}$ & 0,1936079532 & 0,0715012036 & 0,1275823141 & $-0,0568217992$ & $-0,0423962480$ & $-0,0567318046$ & 0,0091988549 \\
\hline $\mathbf{1 5}$ & 0,1389283861 & 0,0816897546 & 0,0256397028 & 0,0184437536 & 0,0245434541 & 0,0133137966 & $-0,0564344256$ \\
\hline
\end{tabular}


Tablo 13. 20. Dereceden FIR Filtre Katsayllart

\begin{tabular}{c|l|l|l|l|l|l|l}
$b_{k}$ & \multicolumn{1}{|c|}{ GA } & \multicolumn{1}{|c|}{ PSO } & DE & ABC & BWO & SSA & HA \\
\hline $\mathbf{1}$ & $-0,0033811821$ & 0,0175592464 & $-0,0601112014$ & $-0,0578069204$ & 0,0077715936 & $-0,0530745088$ & 0,0064063308 \\
\hline $\mathbf{2}$ & $-0,0462980621$ & 0,0381579022 & $-0,0555755869$ & $-0,0159765414$ & $-0,0465599395$ & $-0,1323066120$ & $-0,0188800339$ \\
\hline $\mathbf{3}$ & $-0,0295883608$ & $-0,0101714747$ & 0,0458500721 & 0,0439186990 & $-0,0216639337$ & $-0,1854581657$ & 0,0151125094 \\
\hline $\mathbf{4}$ & 0,0189331394 & $-0,0473051888$ & 0,0924368876 & 0,0194086241 & 0,0770911587 & $-0,1209403405$ & 0,0256004566 \\
\hline $\mathbf{5}$ & 0,0023724722 & 0,0033683464 & $-0,0320004440$ & $-0,0308625424$ & 0,1618414694 & $-0,0648454818$ & $-0,0594649658$ \\
\hline $\mathbf{6}$ & $-0,0691887359$ & 0,0572983744 & $-0,1036610003$ & 0,0606181756 & 0,2198065707 & 0,0590234369 & $-0,1919866175$ \\
\hline $\mathbf{7}$ & $-0,0459082860$ & 0,0060020888 & 0,0643875032 & 0,0359068784 & 0,3005765214 & 0,2190523910 & $-0,2188633345$ \\
\hline $\mathbf{8}$ & 0,0681952929 & $-0,0671818356$ & 0,2802087315 & $-0,0809332743$ & 0,3271147311 & 0,3801404589 & $-0,1927540556$ \\
\hline $\mathbf{9}$ & 0,1142513080 & $-0,0116751613$ & 0,1968921480 & $-0,1831570692$ & 0,1609764314 & 0,2823883255 & $-0,2292290313$ \\
\hline $\mathbf{1 0}$ & 0,0633238630 & 0,0987934115 & $-0,1834491596$ & $-0,0195379737$ & $-0,1362537623$ & 0,0283429928 & $-0,2884933766$ \\
\hline $\mathbf{1 1}$ & 0,1026685527 & 0,0628877772 & $-0,3892440799$ & 0,3378236810 & $-0,2286149974$ & $-0,0961215249$ & $-0,1604743685$ \\
\hline $\mathbf{1 2}$ & 0,3120519455 & $-0,0714739802$ & $-0,3002008093$ & 0,4856536083 & $-0,0289007573$ & 0,0386000436 & 0,1419362699 \\
\hline $\mathbf{1 3}$ & 0,4339632149 & $-0,0190135616$ & $-0,0990358261$ & 0,2715336732 & 0,1617914563 & 0,2053680944 & 0,2972913432 \\
\hline $\mathbf{1 4}$ & 0,2321729616 & 0,2775313699 & $-0,0858936169$ & 0,0113265155 & 0,1079995420 & 0,1721483312 & 0,1003763574 \\
\hline $\mathbf{1 5}$ & $-0,1171914062$ & 0,4875204674 & $-0,1107580559$ & $-0,0243546533$ & $-0,1137014249$ & $-0,0137772453$ & $-0,1749820293$ \\
\hline $\mathbf{1 6}$ & $-0,2289862449$ & 0,3491358122 & $-0,0592700786$ & 0,0858461691 & $-0,1304559535$ & $-0,0902486994$ & $-0,1867767452$ \\
\hline $\mathbf{1 7}$ & $-0,0607012953$ & 0,0330711105 & $-0,0206409018$ & 0,0726695075 & 0,0211187036 & 0,0484200457 & 0,0132982178 \\
\hline $\mathbf{1 8}$ & 0,1083442307 & $-0,1233278205$ & $-0,0341552720$ & $-0,0158368469$ & 0,0981416455 & 0,1469164814 & 0,1233845871 \\
\hline $\mathbf{1 9}$ & 0,0962592157 & $-0,0651787898$ & $-0,0666078499$ & $-0,0353491040$ & 0,0154096096 & 0,0754289620 & 0,0559173155 \\
\hline $\mathbf{2 0}$ & 0,0100739639 & 0,0122628758 & $-0,0511084412$ & $-0,0275088616$ & $-0,0525667031$ & 0,0127303557 & $-0,0313606285$
\end{tabular}

Tablo 14. 25. Dereceden FIR Filtre Katsayllarl

\begin{tabular}{|c|c|c|c|c|c|c|c|}
\hline$b_{k}$ & GA & rol & 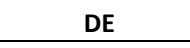 & & & & \\
\hline 1 & $-0,0104140358$ &, 0418676106 & 0,0814172151 & $-0,0260792432$ & 0460874454 & $-0,0734783334$ & 0,0163967584 \\
\hline 2 & 0,0115130181 &, 0326895177 & 1692957137 & $-0,1219835806$ & 168747521 & $-0,1344271728$ & 1166386561 \\
\hline 3 & 06355 & 468829 & 539260751 & 0,0005017398 & 9341446 & $-0,0099089674$ & 911 \\
\hline 4 & 0,0525470661 & 634240 & ,1691508568 & 0,0586392862 & 68765064 & 0,01628 & 3897 \\
\hline 5 & 6269 & 37628 & 0,2276059447 & 632 & 269225 & $-0,00$ & 2996 \\
\hline 6 & 364 & 919 & 23744 & 56 & 71027 & 361 & 8331 \\
\hline 7 & 159 & 34648 & 599632 & 306 & 51338 & 527 & 192 \\
\hline 8 & 50073 & 846527 & 658764 & 3748240 & 25708957 & 1832969 & 2243228 \\
\hline 9 & 288468 & 42655 & 0,027 & 3593 & 816887 & 481 & 58234 \\
\hline 10 & $-0,1737576067$ & 39771 & 927493 & 3039551 & 8459129 & $-0,02$ & 689667 \\
\hline 11 & 2070725 & 632151 & 0,1120228632 & 2225766 & 427230 & $-0,0$ & 522209 \\
\hline 12 & 66061 & 20706 & 759422 & 5037 & 419924 & 57486 & 0398988 \\
\hline 13 & 822 & 5076 & & 0,0 & 1448 & 7358 & 77173 \\
\hline 14 & 57412 & 7348284 & 6857063 & 070226 & 82280 & 7373630 & 462830 \\
\hline 15 & 0,2048254541 & 0,0577943899 & $-0,2355998743$ & $-0,0599300087$ & 21001040 & $-0,3738862731$ & $-0,1050008186$ \\
\hline 16 & $-0,0208179219$ & 0,2488621563 & $-0,0361419304$ & 3821611 & 0,1671534720 & $-0,2579583296$ & 974645 \\
\hline 17 & $-0,0758341877$ & 0,1384106126 & 0,2479306526 & 0,1148605529 & $-0,0644064557$ & 0,0229807695 & 0,1341225619 \\
\hline 18 & 0,1293932968 & $-0,0922862215$ & 0,2176753018 & 0,0546091523 & $-0,2237125261$ & 0,1180328215 & $-0,0601613164$ \\
\hline 19 & 0,3005814116 & $-0,1264709892$ & $-0,0634432641$ & $-0,0394522592$ & $-0,1085083842$ & 0,0794660756 & $-0,1058747880$ \\
\hline 20 & 0,1996846720 & 0,0262661921 & $-0,1727039888$ & $-0,0034475373$ & 0,1385573767 & $-0,0861148384$ & 0,0077250872 \\
\hline 21 & $-0,0080030300$ & 0,1075909962 & $-0,0354902424$ & 0,0108863662 & 0,1671373324 & $-0,1570396275$ & 0,0539814290 \\
\hline 22 & $-0,0343566971$ & 0,0308586753 & 0,1021509943 & 39343 & $-0,0644064557$ & $-0,1822617633$ & $-0,0458011695$ \\
\hline 23 & 0,0958058195 & $-0,0463133838$ & 0,0509787553 & 0,0108560729 & $-0,2553595592$ & $-0,1648312246$ & $-0,1621825021$ \\
\hline 24 & 0,1580022389 & $-0,0221211183$ & $-0,0008088349$ & $-0,0279054916$ & $-0,2222829818$ & $-0,0568148245$ & $-0,1433379153$ \\
\hline 25 & 0,0792746254 & 0,0234044640 & $-0,0428666066$ & $-0,0841764415$ & $-0,0638886745$ & 0,0282808168 & $-0,0584621167$ \\
\hline
\end{tabular}


European Journal of Science and Technology

Tablo 15. 30. Dereceden FIR Filtre Katsayılart

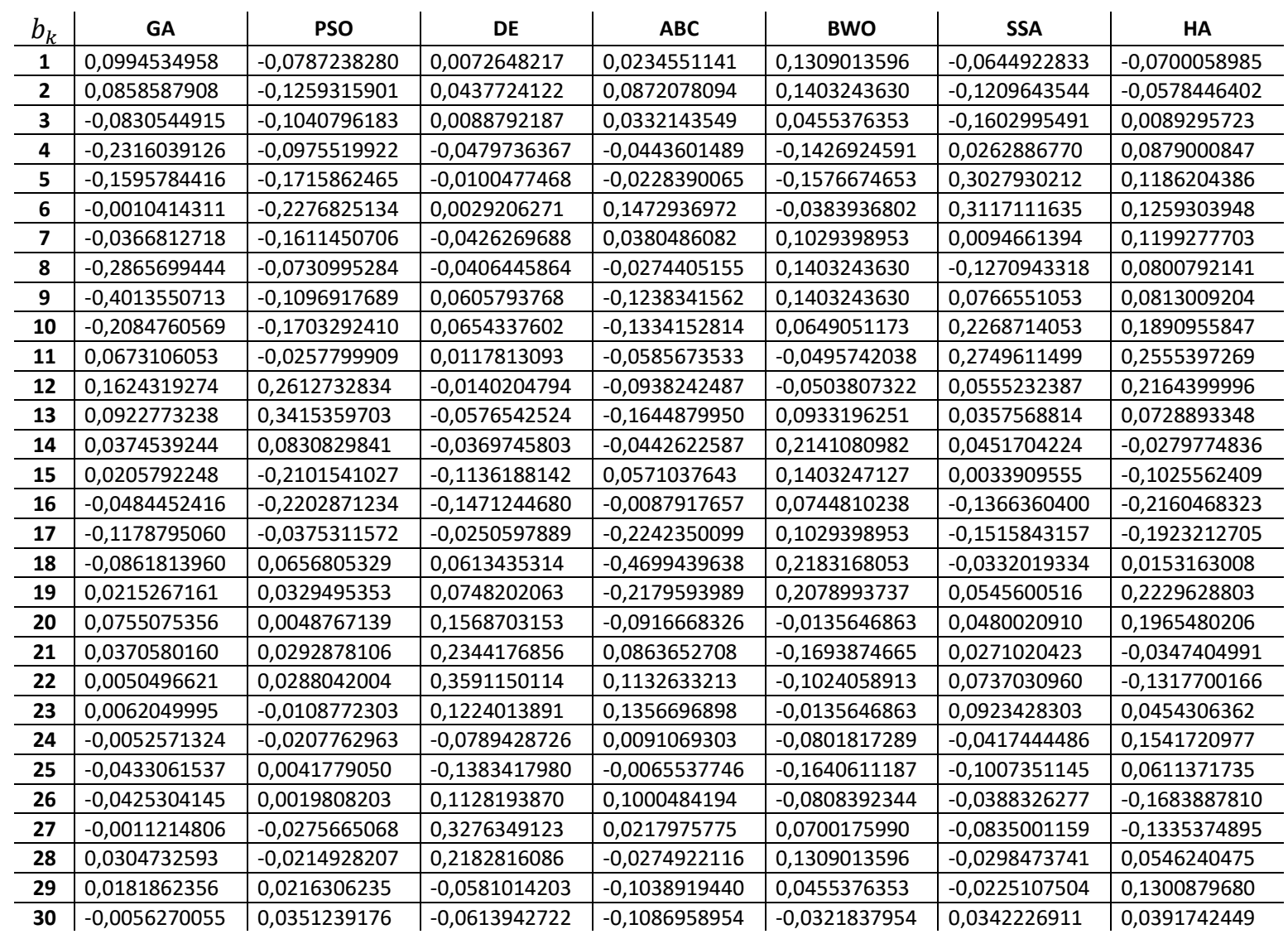


Avrupa Bilim ve Teknoloji Dergisi

\begin{tabular}{|c|c|c|c|c|c|c|c|c|}
\hline D & & GA & PSO & $\mathrm{DE}$ & $\mathrm{ABC}$ & BWO & SSA & HA \\
\hline \multirow{7}{*}{5} & Pr1 & 0,0593434466 & 0,0594024620 & 0,0595195287 & 0,0595195752 & 0,0594959773 & 0,0589625866 & 0,0594211081 \\
\hline & Pr2 & 0,0000000000 & 0,0000000000 & 0,0000000000 & 0,0000000000 & 0,0000000000 & 0,0000000000 & 0,0000000000 \\
\hline & AS & 39,5418904597 & 39,5446037865 & 39,5013035982 & 39,5013505962 & 39,6391940903 & 39,1266190403 & 39,5408317812 \\
\hline & Ep & 9,7321221860 & 9,7291345810 & 9,6886666303 & 9,6886611929 & 9,6998874224 & 9,7976723871 & 9,7293565897 \\
\hline & Es & 17,2509600841 & 17,2538709832 & 17,2942792289 & 17,2942847567 & 17,2885000418 & 17,2054134359 & 17,2536018617 \\
\hline & Et & 0,0764470016 & 0,0764793119 & 0,0761666656 & 0,0761668305 & 0,0765843145 & 0,0756709266 & 0,0764870766 \\
\hline & \begin{tabular}{|l|} 
Total \\
Iter Time \\
\end{tabular} & 595,0889216 & 601,2257538 & 1088,2517399 & 955,5287567 & 1168,2112419 & 1054,5631544 & 328,6004288 \\
\hline \multirow{7}{*}{10} & Pr1 & 0,0864501439 & 0,0896391510 & 0,0705766299 & 0,0864280029 & 0,0731385240 & 0,0740460425 & 0,1074763963 \\
\hline & Pr2 & 0,0598027936 & 0,0526520586 & 0,0701249029 & 0,0500631311 & 0,0953149584 & 0,0864287955 & 0,0786609936 \\
\hline & AS & 48,5840422443 & 49,4923699892 & 56,3592805267 & 48,0882881403 & 48,8482745184 & 48,4460064153 & 52,3202771632 \\
\hline & Ep & 5,8536577189 & 5,8242489230 & 5,8841515390 & 5,4936363123 & 8,3255973404 & 5,8546255799 & 8,0014373933 \\
\hline & Es & 5,7039957557 & 5,7195837685 & 5,9981590321 & 6,2283007993 & 6,0240741443 & 6,4448625494 & 6,1291241838 \\
\hline & Et & 0,0800412827 & 0,0818632112 & 0,0729899362 & 0,0840330300 & 0,0518801850 & 0,0755895661 & 0,0780433887 \\
\hline & \begin{tabular}{|l} 
Total \\
Iter Time
\end{tabular} & 585,2937285 & 599,7240904 & 1084,5020986 & 1123,2484986 & 1681,7931722 & 1073,4982447 & 323,1688785 \\
\hline \multirow{7}{*}{15} & Pr1 & 0,0223376644 & 0,0693940035 & 0,1470169178 & 0,0679887673 & 0,0247681135 & 0,0988219296 & 0,0660177127 \\
\hline & Pr2 & 0,0118643594 & 0,0208362155 & 0,0754536395 & 0,0000302875 & 0,1197731314 & 0,1074747511 & 0,0151820056 \\
\hline & AS & 39,9888706194 & 47,6780982350 & 41,9677549058 & 45,9787710854 & 46,7433712331 & 44,1612382994 & 45,2780069664 \\
\hline & Ep & 2,0740423547 & 3,1628445274 & 5,4043384182 & 3,0186045420 & 9,3630245426 & 6,0188895620 & 3,0788439456 \\
\hline & Es & 6,7643667391 & 4,3008000062 & 3,4083329355 & 4,5818607118 & 2,9643344990 & 4,9277854981 & 4,7665198647 \\
\hline & Et & 0,0793421284 & 0,0866637210 & 0,0753885478 & 0,0864330500 & 0,0454790765 & 0,0841650477 & 0,0860262526 \\
\hline & \begin{tabular}{|l|} 
Total \\
Iter Time \\
\end{tabular} & 585,3298999 & 641,4800197 & 1095,0229301 & 1698,4634557 & 2442,2243558 & 1110,3831997 & 321,5911630 \\
\hline \multirow{7}{*}{20} & Pr1 & 0,0495188894 & 0,0858183169 & 0,1234478094 & 0,0563787576 & 0,0177516317 & 0,1475834064 & 0,0905162264 \\
\hline & \begin{tabular}{|l|} 
Pr2 \\
\end{tabular} & 0,0228478972 & 0,0254855111 & 0,0654537894 & 0,0408536600 & 0,0995643288 & 0,0616873302 & 0,0488522043 \\
\hline & AS & 51,8258960682 & 52,7273048624 & 57,2047510794 & 39,3834183136 & 41,6858055154 & 42,2693631621 & 49,6514388985 \\
\hline & Ep & 2,7353646144 & 2,7230984622 & 2,9403986910 & 2,6027917894 & 2,8690624471 & 7,8515597761 & 2,9252163745 \\
\hline & Es & 2,6593446985 & 2,4117994952 & 5,1060851393 & 6,0402229668 & 5,0417129531 & 3,1818827077 & 3,3216420579 \\
\hline & Et & 0,0759525504 & 0,0839585100 & 0,0540928764 & 0,0861736408 & 0,0695270370 & 0,0695261338 & 0,0845561348 \\
\hline & \begin{tabular}{|l|} 
Total \\
Iter Time \\
\end{tabular} & 585,0558253 & 636,2222970 & 1148,7272777 & 1573,9477310 & 2953,8590282 & 959,5629777 & 320,4762307 \\
\hline \multirow{7}{*}{25} & Pr1 & 0,0948134109 & 0,0596211256 & 0,2666441996 & 0,1966467378 & 0,1701888032 & 0,2245967716 & 0,1771288236 \\
\hline & Pr2 & 0,1017000359 & 0,0093514840 & 0,0212525270 & 0,0284621849 & 0,1528877793 & 0,1181256243 & 0,0361069301 \\
\hline & AS & 51,6025573127 & 48,2108047009 & 38,0358126116 & 23,4010129179 & 52,0579935098 & 33,2488247266 & 50,4052165461 \\
\hline & Ep & 3,5539673740 & 1,3696070453 & 9,4453527886 & 8,4807077662 & 10,9585575983 & 8,5330794749 & 6,0584071610 \\
\hline & Es & 1,9110853448 & 2,2226798157 & 5,2054177414 & 24,4354141712 & 1,6666712939 & 7,5236565774 & 1,4554924932 \\
\hline & Et & 0,0729452694 & 0,0850164352 & 0,1175301674 & 0,0838014325 & 0,0623978817 & 0,0522130450 & 0,0824674847 \\
\hline & \begin{tabular}{|l|} 
Total \\
Iter Time \\
\end{tabular} & 583,8005445 & 632,4018260 & 825,4331076 & 1700,5690899 & 3731,0826947 & 1094,3049925 & 320,6292265 \\
\hline \multirow{7}{*}{30} & Pr1 & 0,0411372442 & 0,0514494478 & 0,1563796663 & 0,2487828526 & 0,1907146256 & 0,1756235735 & 0,1868355394 \\
\hline & Pr2 & 0,0412137438 & 0,0025963466 & 0,1064111606 & 0,0910056709 & 0,1749532563 & 0,0400919159 & 0,0213999405 \\
\hline & AS & 49,7768308453 & 49,5106217299 & 24,7181545258 & 21,0697535023 & 35,4347131094 & 26,5297297272 & 32,4847624768 \\
\hline & Ep & 1,6055146206 & 0,8594248735 & 8,5254196845 & 16,3285063100 & 14,4331364449 & 15,4863211510 & 4,2613872952 \\
\hline & Es & 1,5935396278 & 1,5637156082 & 14,5932232155 & 31,9192644490 & 4,6517984840 & 14,9935958425 & 5,4057150421 \\
\hline & Et & 0,0718046040 & 0,0844653825 & 0,0834938979 & 0,0879216954 & 0,0396341486 & 0,0698273400 & 0,0995580105 \\
\hline & \begin{tabular}{|l|} 
Total \\
Iter Time
\end{tabular} & 584,4548374 & 600,0177770 & 661,7768563 & 1056,0331673 & 4211,5440303 & 1098,5108274 & 320,8809111 \\
\hline
\end{tabular}


Tablo 16. En İyi Sonuçlar

\begin{tabular}{|c|c|c|}
\hline \multirow{7}{*}{ 5. Derece } & PBMax Ripple & SSA \\
\hline & PBMin Ripple & 0 \\
\hline & AS & $\mathrm{BWO}$ \\
\hline & PB Error & $A B C$ \\
\hline & SB Error & SSA \\
\hline & TB Error & SSA \\
\hline & Total Iter Time & $\mathrm{HA}$ \\
\hline \multirow{7}{*}{ 10. Derece } & PBMax Ripple & $\mathrm{DE}$ \\
\hline & PBMin Ripple & $A B C$ \\
\hline & AS & $\mathrm{DE}$ \\
\hline & PB Error & $A B C$ \\
\hline & SB Error & $\mathrm{GA}$ \\
\hline & TB Error & BWO \\
\hline & Total Iter Time & $\mathrm{HA}$ \\
\hline \multirow{7}{*}{ 15. Derece } & PBMax Ripple & GA \\
\hline & PBMin Ripple & $A B C$ \\
\hline & AS & PSO \\
\hline & PB Error & GA \\
\hline & SB Error & BWO \\
\hline & TB Error & BWO \\
\hline & Total Iter Time & $\mathrm{HA}$ \\
\hline \multirow{7}{*}{ 20. Derece } & PBMax Ripple & BWO \\
\hline & PBMin Ripple & GA \\
\hline & AS & $\mathrm{DE}$ \\
\hline & PB Error & $A B C$ \\
\hline & SB Error & PSO \\
\hline & TB Error & $\mathrm{DE}$ \\
\hline & Total Iter Time & $\mathrm{HA}$ \\
\hline \multirow{7}{*}{ 25. Derece } & PBMax Ripple & PSO \\
\hline & PBMin Ripple & PSO \\
\hline & AS & BWO \\
\hline & PB Error & PSO \\
\hline & SB Error & $\mathrm{HA}$ \\
\hline & TB Error & SSA \\
\hline & Total Iter Time & $\mathrm{HA}$ \\
\hline \multirow{7}{*}{ 30. Derece } & PBMax Ripple & GA \\
\hline & PBMin Ripple & PSO \\
\hline & AS & $\mathrm{GA}$ \\
\hline & PB Error & PSO \\
\hline & SB Error & PSO \\
\hline & TB Error & BWO \\
\hline & Total Iter Time & $\mathrm{HA}$ \\
\hline
\end{tabular}

Tablo 17. En Kötü Sonuçlar

\begin{tabular}{|c|c|c|}
\hline \multirow{7}{*}{ 5. Derece } & PBMax Ripple & $A B C$ \\
\hline & PBMin Ripple & 0 \\
\hline & AS & SSA \\
\hline & PB Error & SSA \\
\hline & SB Error & $A B C$ \\
\hline & TB Error & BWO \\
\hline & Total Iter Time & BWO \\
\hline \multirow{7}{*}{ 10. Derece } & PBMax Ripple & $\mathrm{HA}$ \\
\hline & PBMin Ripple & BWO \\
\hline & AS & $A B C$ \\
\hline & PB Error & BWO \\
\hline & SB Error & SSA \\
\hline & TB Error & $A B C$ \\
\hline & Total Iter Time & BWO \\
\hline \multirow{7}{*}{ 15. Derece } & PBMax Ripple & $\mathrm{DE}$ \\
\hline & PBMin Ripple & BWO \\
\hline & AS & GA \\
\hline & PB Error & BWO \\
\hline & SB Error & GA \\
\hline & TB Error & PSO \\
\hline & Total Iter Time & BWO \\
\hline \multirow{7}{*}{ 20. Derece } & PBMax Ripple & SSA \\
\hline & PBMin Ripple & BWO \\
\hline & AS & $A B C$ \\
\hline & PB Error & SSA \\
\hline & SB Error & $A B C$ \\
\hline & TB Error & $A B C$ \\
\hline & Total Iter Time & BWO \\
\hline \multirow{7}{*}{ 25. Derece } & PBMax Ripple & $\mathrm{DE}$ \\
\hline & PBMin Ripple & BWO \\
\hline & AS & $A B C$ \\
\hline & PB Error & BWO \\
\hline & SB Error & $A B C$ \\
\hline & TB Error & $\mathrm{DE}$ \\
\hline & Total Iter Time & BWO \\
\hline \multirow{7}{*}{ 30. Derece } & PBMax Ripple & $A B C$ \\
\hline & PBMin Ripple & BWO \\
\hline & AS & $A B C$ \\
\hline & PB Error & $A B C$ \\
\hline & SB Error & $A B C$ \\
\hline & TB Error & $\mathrm{HA}$ \\
\hline & Total Iter Time & BWO \\
\hline
\end{tabular}

\section{Filtre Uygulaması}

Literatürde yaygın olarak 20. dereceden FIR filtreler kullanılarak performansları karşıllaştııılmıştır. Bu çalışmada da 20. dereceden normalize geçirme bandı frekansı $0.49 \mathrm{pi}$, normalize durdurma bandı frekansı 0.51 pi olan yukarıda bahsi geçen algoritmalarda en iyi ve en kötü durdurma bandı bastırma oranına sahip olan sırasıyla $\mathrm{DE}$ ve $\mathrm{ABC}$ algoritmaları kullanılarak filtre tasarlanmış ve sentetik sinyal üzerine uygulanmıştır. Sentetik sinyal 100,300 ve 450 hertz bileşenlerinden oluşmakta olup aşağıdaki kod bloğu kullanılarak tasarlanmıştır.

Fs $=1000 ; \quad \%$ Örnekleme Frekans1

$\mathrm{T}=1 / \mathrm{Fs} ; \quad \%$ Örnekleme Periyodu

$\mathrm{t}=0: 1 / \mathrm{Fs}: 0.25 ; \quad \%$ Sinyal Uzunluğu

f1 $=100 ; \quad \% 1$. Sinyal İçin Frekans

$\mathrm{f} 2=300 ; \quad \%$ 2. Sinyal İçin Frekans

f3 $=450 ; \quad \% 3$. Sinyal İçin Frekans

data $1=\sin (2 * \mathrm{pi} * \mathrm{f} 1 * \mathrm{t}) ; \quad \% 1$. Sinyal

data $2=\sin (2 *$ pi $* \mathrm{f} 2 * \mathrm{t}) ; \quad \% 2$. Sinyal

data $3=\sin \left(2 * \mathrm{pi}^{*} \mathrm{f} 3 * \mathrm{t}\right) ; \quad \% 3$. Sinyal 
data $=$ data $1+$ data $2+$ data3; \% Sentetik Sinyal

20. dereceden normalize geçirme bandı frekansı 0.49 pi, normalize durdurma band frekansı 0.51 pi olan $D E$ ve $A B C$ algoritmaları ile elde edilen filtrelerin frekans yanıtları Şekil9' da verilmiştir.
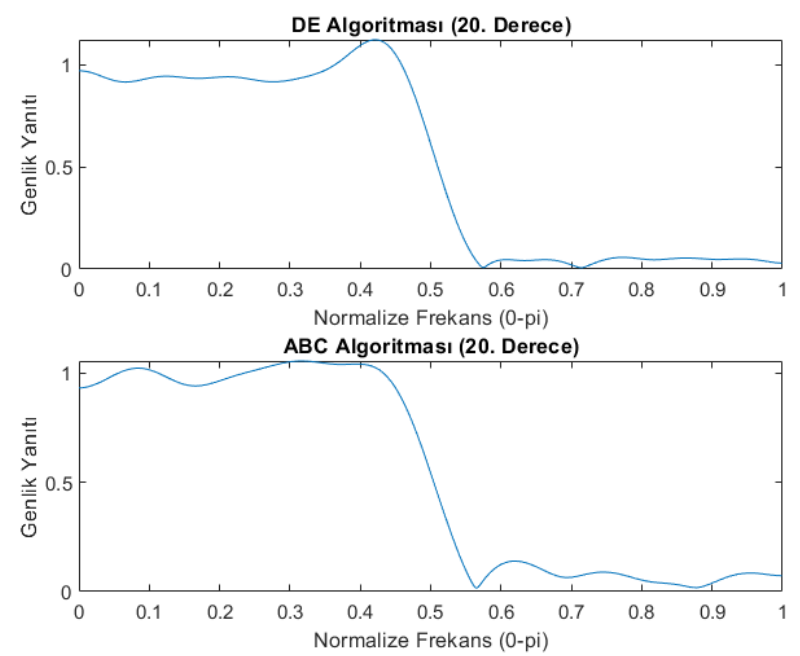

Şekil 9 20. Dereceden Filtre Frekans Yanıtı

Sentetik sinyalin DE ve ABC algoritması ile filtrelenmiş hallerinin genlik zaman grafiği Şekil-10'da verildiği üzeredir.
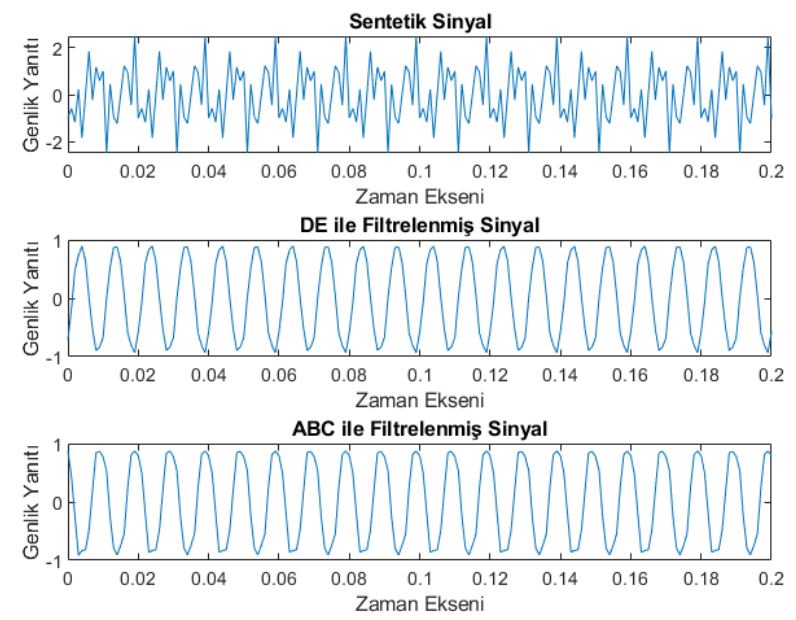

Şekil 10 DE ile Filtrelenmiş Sinyal

Bu sinyallere ait Hızlı Fourier Dönüşümü yapılarak elde edilen frekans-genlik spektrumu Şekil-11'de verilmiştir.
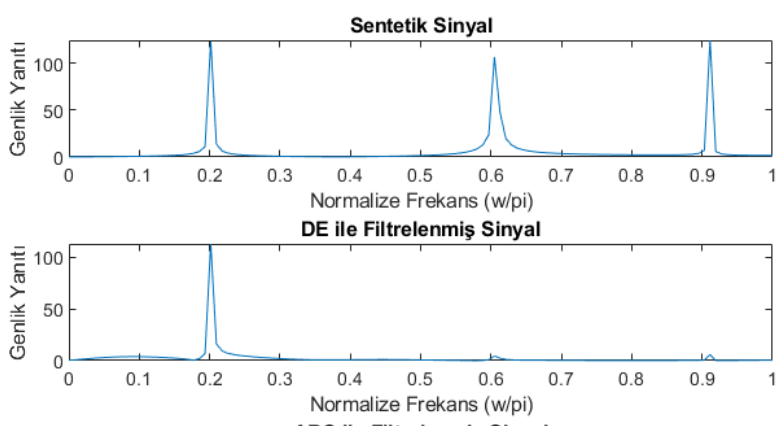

ABC ile Filtrelenmiş Sinyal

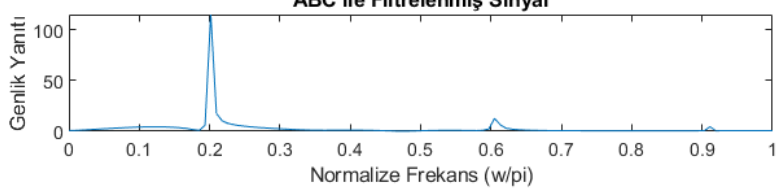

Şekil 11 DE ile Filtrelenmiş Sinyalin Fourier Dönüşümü

Şekil-11 görsel olarak incelendiğinde tasarımı yapılmış filtreye göre düşük frekans bileşenlerini geçirip, yüksek frekans bileşenlerini durdurması gereken filtrelerde durdurma bandı bastırma oranı " 57,2047510794 " olan DE algoritması daha iyi sonuç verirken durdurma bandı bastırma oranı "39,3834183136" olan ABC algoritması daha kötü sonuç vermiştir. $\mathrm{Bu}$ sonuçları değerlendirmeye yönelik sayısal performans analizi için aşağıda verilen kod bloğu ile sentetik sinyal ve filtrelenmiş sinyal durdurma bandı güç oranları, hesaplanarak Tablo-19'da verilmiştir.

y1=fft(data);

$\%$ Sentetik Sinyal FFT

y2=fft(filtered);

$\%$ Filtrelenmiş Sinyal FFT

p1=abs $(y 1(1:$ length $($ data $) / 2))$;

$\%$ Sentetik Sinyal durdurma band 1

p2=abs $(y 2(1:$ length $($ data $) / 2))$;

$\%$ Filtrelenmiş Sinyal durdurma band 1

p11=sum(p1(length(p1)/2:end).^2)/(length(p1)/2);

$\%$ Sentetik Sinyal durdurma band 1

p21=sum(p2(length(p2)/2:end).^2)/(length(p2)/2);

$\%$ Filtrelenmiş Sinyal durdurma bandı

Oran $=20 * \log 10(\mathrm{p} 11 / \mathrm{p} 21)$;

$\%$ Durdurma bandı sinyal-gürültü oranı

Tablo 18 Performans Karşılaştırması

\begin{tabular}{l|l|l} 
& DE & ABC \\
\hline $\begin{array}{l}\text { Sinyal- } \\
\text { Gürültü Oranı }\end{array}$ & 53.2203634514597 & 41.3640199537679 \\
&
\end{tabular}

\section{Tartışma}

$\mathrm{Bu}$ çalışmada FIR filtre tasarımına yönelik metasezgisel algoritmalar kullanan bir yaklaşım önerilmiştir. $\mathrm{Bu}$ amaç doğrultusunda önerilen sistemin performansı PSO, DE, ABC, GA, HA, BWO, SSA algoritmaları ile karşılaştırılmıştır. Performans parametreleri olarak geçirme band1 maksimum dalgalanma miktarı, durdurma bandı minimum dalgalanma miktarı, desibel cinsinden durdurma band1 zayıflaması, geçirme bandı toplam hatası, durdurma bandı toplam hatası, geçiş bandı toplam hatası, toplam iterasyon süresi kullanışmıştır. Filtre derecesi 5'ten 30'a kadar değişen 
derecelerde metasezgisel algoritmalarla gerçekleştirilen filtreler karşılaştırıldığında dereceye göre ve performans parametrelerine göre algoritmaların başarısının değiştiği Tablo-17 ve Tablo-18'den de görülmektedir. $\mathrm{Bu}$ nedenle önerilen yaklaşımla en iyi filtre tasarımına ait metasezgisel algoritmanın hangisinin en iyi olduğunu söylemek mümkün değildir. Çalışmanın ikinci aşamasında örnek olarak tasarlanan 20. dereceden filtrelerin performansı sentetik bir sinyal üzerinde analiz edilmiştir. En iyi ve en kötü duruma göre karşılaştırılma yapıldığında başarılı bir filtre tasarımında Tablo-19'da görüldüğü gibi SNR oranında önemli farklılılar bulunmaktadır.

İleriki çalışmalarda ortaya konan bu filtre tasarımına ait yöntem ile iki boyutlu filtrelerin tasarımı planlanmaktadır. Önerilen yaklaşımın farklı sinyal uygulamalarında ve görüntü analizinde kullanılabileceği görülmektedir.

\section{Kaynakça}

Aggarwal, A., Rawat, T. K. \& Upadhyay, D. K. (2016). Design of optimal digital FIR filters using evolutionary and swarm optimization techniques. AEU - International Journal of Electronics and Communications, 70(4), 373385. https://doi.org/10.1016/j.aeue.2015.12.012

Bose, D., Biswas, S., Vasilakos, A. V. \& Laha, S. (2014). Optimal filter design using an improved artificial bee colony algorithm. Information Sciences, 281, 443-461. https://doi.org/10.1016/j.ins.2014.05.033

Chen, S. \& Luk, B. L. (2010). Digital IIR filter design using particle swarm optimisation. International Journal of Modelling, Identification and Control, 9(4), 327-335.

Clerc, M. \& Kennedy, J. (2002). The particle swarmexplosion, stability, and convergence in a multidimensional complex space. IEEE Transactions on Evolutionary Computation, 6(1), 58-73.

Geem, Z. W., Kim, J. H. \& Loganathan, G. V. (2001). A new heuristic optimization algorithm: harmony search. Simulation, 76(2), 60-68.

Gupta, L. \& Mehra, R. (2011). Modified PSO based Adaptive IIR Filter Design for System Identification on FPGA. International Journal of Computer Applications, 22(5), 17. https://doi.org/10.5120/2583-3569

Hayyolalam, V. \& Pourhaji Kazem, A. A. (2020). Black Widow Optimization Algorithm: A novel meta-heuristic approach for solving engineering optimization problems. Engineering Applications of Artificial Intelligence, 87(July 2019), 103249. https://doi.org/10.1016/j.engappai.2019.103249

Holland, J. H. \& others. (1992). Adaptation in natural and artificial systems: an introductory analysis with applications to biology, control, and artificial intelligence. MIT press.

Jain, M., Singh, V. \& Rani, A. (2019). A novel nature-inspired algorithm for optimization: Squirrel search algorithm. Swarm and Evolutionary Computation, 44(November 2017), $148-175$. https://doi.org/10.1016/j.swevo.2018.02.013

Jarraya, B. \& Bouri, A. (2012). Metaheuristic Optimization Backgrounds: A Literature Review. International Journal of Contemporary Business Studies, 3(12), 2156-7506. http://www.akpinsight.webs.com

Karaboga, D. (2005). An idea based on honey bee swarm for numerical optimization.
Karaboga, N. (2005). Digital IIR filter design using differential evolution algorithm. Eurasip Journal on Applied Signal Processing, 2005(8), 1269-1276. https://doi.org/10.1155/ASP.2005.1269

Karaboga, N. (2009). A new design method based on artificial bee colony algorithm for digital IIR filters. Journal of the Franklin Institute, 346(4), 328-348. https://doi.org/10.1016/j.jfranklin.2008.11.003

Karaboga, N. \& Cetinkaya, B. (2004). Design of minimum phase digital IIR filters by using genetic algorithm. Report - Helsinki University of Technology, Signal Processing Laboratory, 46, 29-32.

Karaboga, N. \& Cetinkaya, B. (2006). Design of digital FIR filters using differential evolution algorithm. Circuits, Systems, and Signal Processing, 25(5), 649-660. https://doi.org/10.1007/s00034-005-0721-7

Karaboğa, N. \& Çetinkaya, M. B. (2011). A novel and efficient algorithm for adaptive filtering: Artificial bee colony algorithm. Turkish Journal of Electrical Engineering and Computer Sciences, 19(1), 175-190. https://doi.org/10.3906/elk-0912-344

Karakaş, M. F. \& Latifoğlu, F. (2020). Finite Impulse Response Filter Design Using Squirrel Search Algorithm. 2020 Medical Technologies Congress (TIPTEKNO), 1-4.

Kaya, T. \& İnce, M. C. (2011). Genetik Algoritma Yardımılla Elde Edilen Yüksek Performa nsl Pencere Fonksiyonlarının Yinelemesiz Sayısal Filtre Tasarımında Kullanımı. May, 16-18.

Kumar, A., Subhojit, D. \& Londhe, N. D. (2017). Low-Power FIR Filter Design Using Hybrid Artificial Bee Colony Algorithm with Experimental Validation Over FPGA. Circuits, Systems, and Signal Processing, 36(1), 156-180. https://doi.org/10.1007/s00034-016-0297-4

Kumar, S. \& others. (2021). Review And Analysis Of Optimization Algorithms For Digital Filter Design. Turkish Journal of Computer and Mathematics Education (TURCOMAT), 12(7), 1798-1806.

Latifoğlu, F. (2020). A novel singular spectrum analysis-based multi-objective approach for optimal FIR filter design using artificial bee colony algorithm. Neural Computing and Applications, 32(17), 13323-13341. https://doi.org/10.1007/s00521-019-04680-1

Latifoğlu, F. (2013). A novel approach to speckle noise filtering based on Artificial Bee Colony algorithm: An ultrasound image application. Computer Methods and Programs in Biomedicine, 111(3), 561-569. https://doi.org/10.1016/j.cmpb.2013.05.009

Litwin, L. (2000). FIR and IIR digital filters. IEEE Potentials, 19(4), 28-31.

Manuel, M. \& Elias, E. (2012). Design of Sharp 2D Multiplier-Less Circularly Symmetric FIR Filter Using Harmony Search Algorithm and Frequency Transformation. Journal of Signal and Information Processing, 03(03), 344-351. https://doi.org/10.4236/jsip.2012.33044

Nagasirisha, B. \& Prasad, V. (2020). Noise Removal from EMG Signal Using Adaptive Enhanced Squirrel Search Algorithm. Fluctuation and Noise Letters, 19(04), 2050039.

Najjarzadeh, M. \& Ayatollahi, A. (2008). A comparison between genetic algorithm and PSO for linear phase fir digital filter design. International Conference on Signal Processing Proceedings, ICSP, 2134-2137. 
https://doi.org/10.1109/ICOSP.2008.4697568

Oppenheim, A. V. (1999). Discrete-time signal processing. Pearson Education India.

Parks, T. W. \& Burrus, C. S. (1987). Digital filter design. Wiley-Interscience.

Proakis, J. G. (2001). Digital signal processing: principles algorithms and applications. Pearson Education India.

Reddy, K. S. \& Sahoo, S. K. (2015). An approach for FIR filter coefficient optimization using differential evolution algorithm. AEU - International Journal of Electronics and Communications, 69(1), 101-108. https://doi.org/10.1016/j.aeue.2014.07.019

Saha, S. K., Dutta, R., Choudhury, R., Kar, R., Mandal, D. \& Ghoshal, S. P. (2013). Efficient and accurate optimal linear phase FIR filter design using opposition-based harmony search algorithm. The Scientific World Journal, 2013. https://doi.org/10.1155/2013/320489

Saha, S. K., Kar, R., Mandal, D. \& Ghoshal, S. P. (2014). Harmony search algorithm for infinite impulse response system identification. Computers and Electrical Engineering, $\quad 40(4), \quad 1265-1285$. https://doi.org/10.1016/j.compeleceng.2013.12.016

Sarangi, S. K., Panda, R. \& Abraham, A. (2020). Design of optimal low-pass filter by a new Levy swallow swarm algorithm. Soft Computing, 24(23), 18113-18128. https://doi.org/10.1007/s00500-020-05065-6

Shao, P., Wu, Z., Zhou, X. \& Tran, D. C. (2017). FIR digital filter design using improved particle swarm optimization based on refraction principle. In Soft Computing (Vol. 21, Issue 10, pp. 2631-2642). https://doi.org/10.1007/s00500015-1963-3

Storn, R. \& Price, K. (1997). Differential evolution--a simple and efficient heuristic for global optimization over continuous spaces. Journal of Global Optimization, 11(4), 341-359.

Zhang, G., Gu, Y., Hu, L. \& Jin, W. (2003). A novel genetic algorithm and its application to digital filter design. IEEE Conference on Intelligent Transportation Systems, Proceedings, ITSC, 2, 1600-1605. https://doi.org/10.1109/ITSC.2003.1252754 